\title{
The potential for gamma-emitting radionuclides to contribute to an understanding of erosion processes in South Africa
}

\author{
Ian D. L. Foster ${ }^{1,2}$, John Boardman ${ }^{3,4}$, Adrian L. Collins ${ }^{5}$, Ruth Copeland-Phillips ${ }^{1}$, Nikolaus J. Kuhn ${ }^{6}$, \\ Tim M. Mighall ${ }^{7}$, Simon Pulley ${ }^{5}$, and Kate M. Rowntree ${ }^{2}$ \\ ${ }^{1}$ Department of Environmental and Geographical Sciences, University of Northampton, \\ Northampton, NN2 6JD, UK \\ ${ }^{2}$ Department of Geography, Rhodes University, Grahamstown 6140, Eastern Cape, South Africa \\ ${ }^{3}$ Environmental Change Institute, Oxford Centre for the Environment, University of Oxford, \\ Oxford OX1 3QY, UK \\ ${ }^{4}$ Department of Environmental and Geographical Science, University of Cape Town, \\ Rondebosch 7701, South Africa \\ ${ }^{5}$ Sustainable Soils and Grassland Systems Department, Rothamsted Research, Okehampton, EX20 2SB, UK \\ ${ }^{6}$ Department of Environmental Sciences, University of Basel, Klingelbergstr. 27, 4056 Basel, Switzerland \\ ${ }^{7}$ Department of Geography \& Environment, School of Geosciences, University of Aberdeen,
} Aberdeen, AB24 3UF, UK

Correspondence to: Ian D. L. Foster (ian.foster@northampton.ac.uk)

Published: 3 March 2017

\begin{abstract}
Several research projects undertaken by the authors and others over the last 14 years have used fallout and geogenic radionuclides for understanding erosion processes and sediment yield dynamics in South Africa over the last 100-200 years as European settlers colonised the interior plains and plateaux of the country and imported new livestock and farming techniques to the region. These projects have used two fallout radionuclides $\left({ }^{210} \mathrm{~Pb}\right.$ and $\left.{ }^{137} \mathrm{Cs}\right)$ to date sediments accumulating in reservoirs, farm dams, wetlands, alluvial fans and floodouts and have used other fallout nuclides $\left({ }^{7} \mathrm{Be}\right)$ and long-lived geogenic radionuclides (e.g. $\left.{ }^{40} \mathrm{~K},{ }^{235} \mathrm{U}\right)$ as part of a composite fingerprint exploring contemporary sediment sources and changes to sources through time. While successful in many parts of the world, applying these techniques in Southern Africa has posed a number of challenges often not encountered elsewhere. Here we explore some of the benefits and challenges in using gamma-emitting radionuclides, especially ${ }^{137} \mathrm{Cs}$, in these landscapes. Benefits include the potential for discriminating gully sidewall from topsoil sources, which has helped to identify contemporary gully systems as sediment conduits, rather than sources, and for providing a time-synchronous marker horizon in a range of sedimentary environments that has helped to develop robust chronologies. Challenges include the spatial variability in soil cover on steep rocky hillslopes, which is likely to challenge assumptions about the uniformity of initial fallout nuclide distribution, the paucity of stable (non-eroding) sites in order to estimate atmospheric fallout inventories, and the limited success of ${ }^{210} \mathrm{~Pb}$ dating in some rapidly accumulating high altitude catchments where sediments often comprise significant amounts of sand and gravel. Despite these challenges we present evidence suggesting that the use of gamma-emitting radionuclides can make a significant contribution to our understanding of erosion processes and sediment yield dynamics. Future research highlighted in the conclusion will try to address current challenges and outline new projects established to address them more fully.
\end{abstract}




\section{Introduction}

A number of early Southern Hemisphere studies noted the potential for using fallout radionuclides, including ${ }^{137} \mathrm{Cs}$, for dating sedimentary deposits and fingerprinting sediment sources e.g., Longmore et al. (1983) and Loughran et al. (1990) in Australia. Few studies were undertaken in southern Africa before the 21st Century. Exceptions include the work of Kulander and Strömquist (1989), Strömquist (1991) and Quine et al. (1999) in Lesotho and Owens and Walling (1996) in Zimbabwe. These studies often focused on the value of the technique for assessing erosion and soil redistribution rates.

South Africa, and especially the Eastern Cape, has witnessed high rates of erosion and extensive land degradation that appear in significant part to be associated with the arrival of European settlers from the early 19th Century onwards (Hoffmann and Ashwell, 2001; Boardman et al., 2015), yet few recent systematic studies have attempted to measure rates of erosion or fluvial sediment transport across the country. The most recent compilation of sediment transport data for Africa was published by Vanmaercke et al. (2014), including an accessible on-line database comprising sediment yield data from reservoir surveys and river monitoring. Figure 1 shows the frequency distribution of sediment yields for South Africa extracted from this database to which additional sources have been added (from Weaver, 1988 and Rowntree and Foster, 2012). The data confirm earlier published estimates that sediment yields generally range from $<50$ to $>900 \mathrm{t} \mathrm{km}^{-2} \mathrm{yr}^{-1}$, although the highest is a yield of over $11000 \mathrm{t} \mathrm{km}^{-2} \mathrm{yr}^{-1}$ not included in the Vanmaercke et al. (2014) dataset but measured over 3 years in the Roxeni Dam in the former Ciskei in the 1980s (Weaver, 1988). There are significantly higher yields in the rivers database (median $\left.230 \mathrm{t} \mathrm{km}^{-2} \mathrm{yr}^{-1} ; n=38\right)$ than in estimates from reservoir sedimentation data (median $84 \mathrm{t} \mathrm{km}^{-2} \mathrm{yr}^{-1} ; n=138$ ). This is surprising as the catchment areas are an order of magnitude greater for river than reservoir catchments (4350 and $477 \mathrm{~km}^{2}$ respectively) and only three of the river estimates include bedload data. Current datasets are difficult to use as there are variable time periods in the reservoir and river datasets; very few yield estimates are available from former communal lands that are known to be much more heavily degraded (e.g. Hoffman and Ashwell, 2001) and no account is taken of changes in yield through time (most of the data are pre-21st Century). Our current knowledge of sediment yields is generally poor, yet we know that the lifetime of many reservoirs is under threat from extremely high sedimentation rates as demonstrated by Fig. 1. While models based on the Universal Soil Loss Equation (USLE) or the revised version (RUSLE) have been extensively used in South Africa (e.g. Le Roux et al., 2007), Rowntree (2012) criticised their use as scaling up to catchments introduces landscape storage elements that cannot be accounted for in these simple hillslope plot-based models.

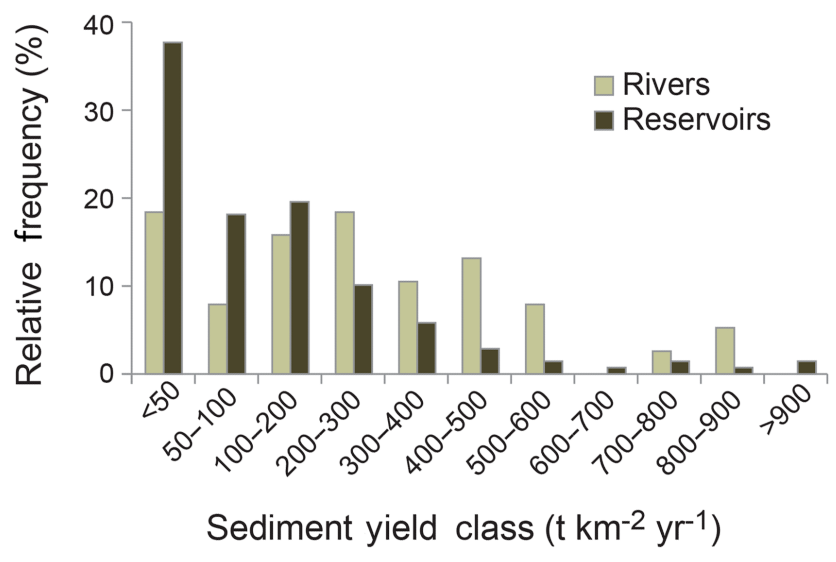

Figure 1. Frequency distribution of sediment yields in the South African Sediment Yield database with additional data (data from Vanmaercke et al., 2014; with additions).

Knowing rates of sediment transport or yield helps to understand the magnitude of the erosion problem but any effective solution to land degradation also requires that we know where the sediment has come from. We have used a range of techniques, including fallout radionuclides, in order to explore methods for reconstructing sediment yields over the last 1-2 centuries and for determining the provenance of that sediment. We have set this work within a conceptual and potential management framework that focuses on connectivity (e.g. Bracken et al., 2015) (see Foster et al., 2012 for detail).

\section{Study area, materials and methods}

Research has mostly focused on the Sneeuburg mountains and the plains of Camdeboo in the northern part of the Eastern Cape, South Africa. The highest mountain is the Kompasberg (2502 m a.s.l.). Geologically, the region is composed of mudstones and sandstones of the Karoo Supergroup (Permian to Triassic age) while dolerite dykes and sills (Jurassic age) dominate ridge tops and peaks. Soils on hillslopes are discontinuous but extensive valley fills, up to $5 \mathrm{~m}$ thick, exist in valley bottoms. The vegetation of the Sneeuberg is a mixture of grassland and shrub and is described in detail by Clark et al. (2009). Valley bottoms and valley side colluvium is often gullied to bedrock and, where badlands exist, A and often B horizons of soils have been stripped away. Annual rainfall ranges from 300 to $500 \mathrm{~mm}$ and is concentrated in the summer months from January through March (Foster et al., 2012).

Over the last 14 years we have quantified rates of sedimentation and/or reconstructed sediment yields in small farm dams using ${ }^{210} \mathrm{~Pb}$ and ${ }^{137} \mathrm{Cs}$ to provide a chronology for each sediment stack. We have collected soil and sediment samples from contributing catchments and used a combination of particle size corrected geochemical, mineral magnetic, radionuclide and colour properties to determine the most likely or 
dominant contemporary sediment sources and to detect any changes in sediment sources through time (see Foster et al., 2012; Pulley and Rowntree, 2016). We have also measured erosion rates on badlands using long term erosion pin surveys (see Boardman et al., 2015).

The present paper focuses on the use of ${ }^{137} \mathrm{Cs}$ for both dating and fingerprinting sediment sources based on our experience of these catchments to date and attempts to explore some of the benefits and challenges involved. All radionuclide data reported here and elsewhere have been obtained using EG\&G Ortec Hyper-Pure Ge detectors in a "well" configuration (40 mm deep; $11 \mathrm{~mm}$ diameter), located at Coventry and Northampton Universities and operated at liquid $\mathrm{N}$ temperatures. Samples were screened to $<125 \mu \mathrm{m}$ diameter (to match previous protocols; see Foster et al., 2007) by dry sieving prior to analysis and count times were typically in excess of 2 days in order to reduce counting errors to ca. $5 \%$ or less. Spectra were processed using Ortec ${ }^{\circledR}$ Gammavision software and activities are expressed as $\mathrm{mBqg}^{-1}$. Limits of detection are typically between 0.2 and $0.6 \mathrm{mBqg}^{-1}$.

\section{Fallout and detection issues}

Southern Hemisphere fallout was much lower than that of the Northern Hemisphere and peaked 1-2 years later than in the north, making detection of the first occurrence of ${ }^{137} \mathrm{Cs}$ in sedimentary deposits more challenging; Foster et al. (2012) now suggest that the first fallout in 1956 is probably undetectable using current detector geometry and count times and that the first occurrence in any sedimentary sequence is more likely to detect the cumulative fallout rise to between 1958 and 1960.

Measurement of potential sediment sources has revealed low (median ca. $2 \mathrm{mBqg}^{-1}$ ) and highly variable ( \pm ca. $2 \mathrm{mBqg}^{-1} @ 5$ th and 95 th percentile) ${ }^{137} \mathrm{Cs}$ activities in topsoils $(n>150)$. Many badland surfaces contain no detectable ${ }^{137} \mathrm{Cs}$, although remnant undisturbed A horizons protected by individual Karoo shrubs within badlands often have detectable ${ }^{137} \mathrm{Cs}$ as well as excess ${ }^{210} \mathrm{~Pb}$ and ${ }^{7} \mathrm{Be}$ (these appear to be in situ soils and not wind-derived). Gully sidewalls, excepting the upper $10-15 \mathrm{~cm}$ of the undisturbed profile, also contain no detectable fallout radionuclides. Cultivated soil profiles have lower activities and the ${ }^{137} \mathrm{Cs}$ extends to ca. $25 \mathrm{~cm}$ depth in the profile.

The high spatial variability in soil cover and depth on steep rocky hillslopes, coupled with the missing soil horizons in badlands, challenges any assumptions made about the likely uniformity of fallout nuclide distribution across these landscapes. Indeed, recent measurements of five $0-3 \mathrm{~cm}$ depth soil samples collected on a systematic grid from a small hillslope hollow on a sandstone lithology (ca. $0.5 \times 0.5 \mathrm{~m}$ in area) revealed that ${ }^{137} \mathrm{Cs}$ could only be measured above limits of detection in 3 of the samples. Likewise, van der Waal (2015) detected ${ }^{137} \mathrm{Cs}$ in only $50 \%$ of 28 surface soil samples col- lected from a small Drakensberg catchment. The combination of these factors suggest that the potential use of ${ }^{137} \mathrm{Cs}$ and other fallout radionuclides for estimating soil redistribution rates, using methods described by Walling and Foster (2016), are questionable at best.

An additional challenge in using fallout radionuclides for estimating soil redistribution rates is a paucity of stable (non-eroding) sites to obtain reference inventories. To date we have four inventories that are considered reliable; two cores in the Sneeuberg (averaging $41 \pm 8 \mathrm{mBq} \mathrm{cm}^{-2}$ ) and two cores on the plains of Camdeboo, receiving much lower rainfall (averaging $35 \pm 6 \mathrm{mBq} \mathrm{cm}^{-2}$ ) (Inventories are decay corrected to 2016).

At high altitude we have had limited success with ${ }^{210} \mathrm{~Pb}$ dating in some rapidly accumulating farm dams where differences between supported and excess ${ }^{210} \mathrm{~Pb}$ activities are within, or close to, the limits of analytical detection, invalidating ${ }^{210} \mathrm{~Pb}$ dating models. ${ }^{210} \mathrm{~Pb}$ dating in lower energy environments has, by contrast, been much more successful (see Foster et al., 2012).

\section{$4 \quad{ }^{137} \mathrm{Cs}$ in farm dam sediments}

${ }^{137} \mathrm{Cs}$ inventories in seven farm dam sediment cores, all decay corrected to 2016, are variable and range from less than 190 to over $1300 \mathrm{mBq} \mathrm{cm}^{-2}$, and are always significantly in excess of local reference inventories. Low inventories appear to be associated either with dams whose walls were breached, and remained unrepaired, or where sediment sources were dominated by badlands, where almost no ${ }^{137} \mathrm{Cs}$ is detectable in topsoil. Most non-breached dams have high post- $1974{ }^{137} \mathrm{Cs}$ activities (when atmospheric fallout had almost ceased) suggesting that ${ }^{137} \mathrm{Cs}$ labelled topsoil continued to be delivered to all of the dams in significant quantities. Independent analysis using mineral magnetism, sediment colour and geochemistry (e.g. Foster et al., 2007) confirm this interpretation suggesting that gully sidewalls are not significant sediment sources but that the gullies themselves increase connectivity at the landscape scale by delivering sediment from more distal topsoil sources.

${ }^{137} \mathrm{Cs}$ profiles in the farm dams rarely mirror those of atmospheric fallout and have often proved equivocal in determining the peak in atmospheric fallout in 1965, unlike their Northern Hemisphere counterparts (see e.g. Walling and Foster, 2016). Lack of a consistent pattern appears to reflect variable delivery of excess ${ }^{210} \mathrm{~Pb}$ to the dams from different contributing sources rather than variations in atmospheric fallout. Example profiles for two dams are given in Fig. 2 and show inconsistent patterns of activity down-core. What is notable, however, is that the activities in dam 37 (Fig. 2a) are much higher than in any topsoil or other potential sources yet measured in any of the catchments sampled (see Sect. 5 below for further discussion). 

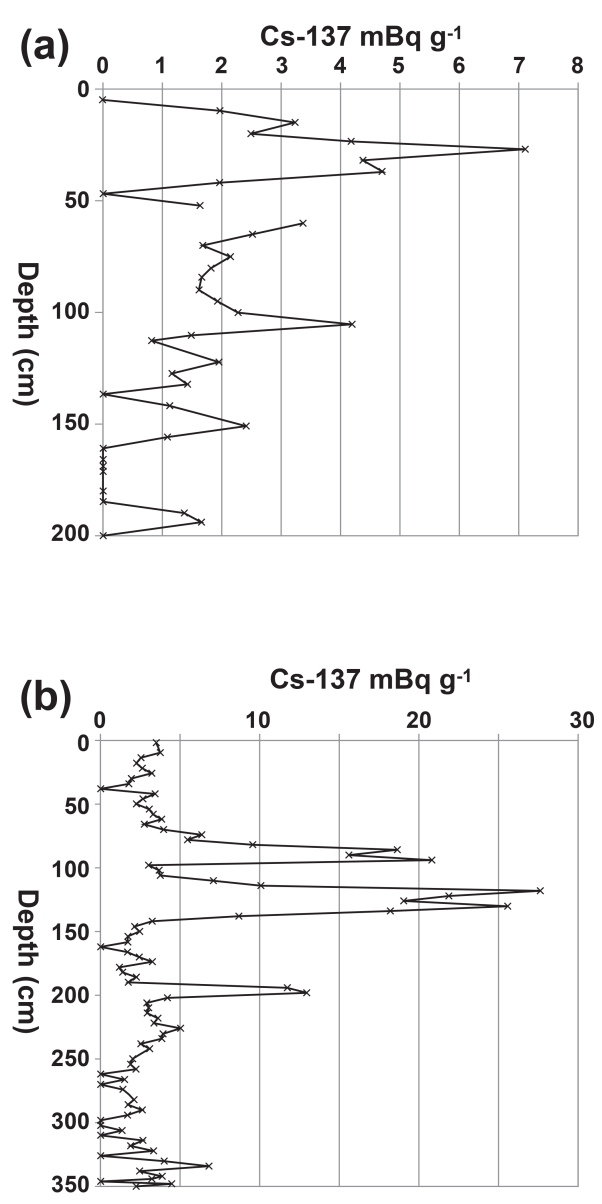

Figure 2. Downcore ${ }^{137} \mathrm{Cs}$ activities in 2 Farm Dams, Hartebeestfontein (Dam 94) and Good Hope (Dam 37) (The hiatus at ca. $55 \mathrm{~cm}$ depth in (a) indicates a period between a dam breach in 1974 and its subsequent repair in 1976).

Similar radionuclide analyses, including the determination of excess ${ }^{210} \mathrm{~Pb}$ profiles, have been undertaken on alluvial fan and floodout deposits (e.g. Foster et al., 2012) and although the 1965 fallout peak is again not clear, the first occurrence of ${ }^{137} \mathrm{Cs}$ across these landscapes in many depositional environments suggests that we can identify a common "time zero" against which rates of accumulation (and sediment yield in reservoirs) might be estimated over a known time period.

Detailed reconstructions of sediment yield have relied on ${ }^{137} \mathrm{Cs}$ and ${ }^{210} \mathrm{~Pb}$ dating of single cores, supplemented by coring dates (or dates of breaching) and the known age of the dams, thereby bracketing the start and end of the depositional sequence. Additional chronological markers have been established from the presence of thin layers of fine gravels deposited in dams by high magnitude floods whose timeframe has been established from local rainfall records (e.g. Foster et al., 2007). Multiple sediment cores are required to quantify the spatial variability in deposition and estimate the volume of sediment deposited over different timescales. The chronol-

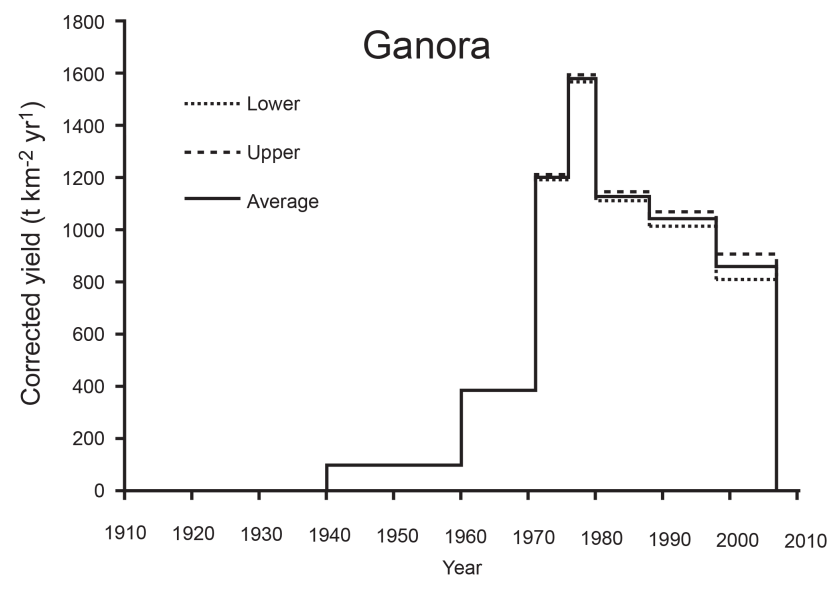

Figure 3. Long term sediment yields in the Ganora Catchment, Eastern Cape, reconstructed from dam sedimentation in Ganora Dam. Lower and upper values account for variable trap efficiencies (see Rowntree and Foster, 2012).

ogy from the master core is then transferred to other cores using time-synchronous markers, such as magnetic susceptibility, which can be measured cheaply and rapidly, and has been shown to be a largely conservative tracer in dam sediments (Pulley et al., 2015). Detailed analysis of these sediment yield records is presented elsewhere (e.g. Foster et al., 2012) but clearly demonstrate that averaging erosion rates over long periods of time misses important information about the timing, magnitude and likely cause of any change in sediment yield (Fig. 3). This analysis suggests that the database shown in Fig. 1 is likely to be less robust as individual estimates of yield have been averaged over several decades in some cases and represent variable time periods and different durations, thereby limiting its value.

We recognise that there is a high cost in determining sediment yield histories using the reconstruction methodologies we have pioneered in South Africa. However, the fact that a common time line can be identified in sedimentary deposits provides an opportunity to obtain much more reliable information on spatial variations in sediment yield by targeting dams and reservoirs known to predate the mid-1950s and using ${ }^{137} \mathrm{Cs}$ to identify a common timeline in the deposited sediment. This means that a full ${ }^{137} \mathrm{Cs}$ profile is not needed once the maximum depth of ${ }^{137} \mathrm{Cs}$ activity has been determined but the approach would only provide a single yield estimate averaged over the last ca. 60 years. Multiple cores would still be required in order to undertake core correlation for the estimation of total sediment mass deposited since the late 1950s, but this could be based on cheaper analytical methods such as environmental magnetism (measurement facilities have been available in South Africa since 2009). Identifying 1958-1960 in lake and reservoir sediments using the fallout nuclide ${ }^{137} \mathrm{Cs}$ would allow a consistent estimate of sediment accumulation, and sediment yield, to be dated back 
to a common national baseline, making estimates between sites directly comparable. The advantage in this approach lies in significantly reducing the number of ${ }^{137} \mathrm{Cs}$ determinations likely to be needed at each site, making it possible to develop a large database at relatively low cost. Targeted full sediment yield reconstructions in carefully selected areas could take sediment yield estimates back to the early 20th century and would provide targets that could be used to demonstrate reductions needed to achieve a "baseline state" (see Foster et al., 2011).

\section{The Good Hope Conundrum}

It has already been noted that the downcore ${ }^{137} \mathrm{Cs}$ profile of Fig. 2b has some activities at least an order of magnitude higher than those measured in any potential source sample collected throughout the region. Even fractionation of five surface soil samples with high bulk activities to $<32 \mu \mathrm{m}$ failed to produce ${ }^{137} \mathrm{Cs}$ activities significantly greater than ca. $12 \mathrm{mBqg}^{-1}$. The smallest 90th percentile of the particle size distribution of 90 samples analysed from the Good Hope dam sediment core was ca. $78 \mu \mathrm{m}$, with over $75 \%$ of them $>150 \mu \mathrm{m}$. Furthermore, there was no statistically significant relationship between the down-core ${ }^{137} \mathrm{Cs}$ activity and particle size suggesting that this is not the major control on ${ }^{137} \mathrm{Cs}$ activities. Several questions therefore arise concerning the possible controls on these extremely high activities which are discussed briefly below.

In order to investigate other potential controls, such as the co-precipitation of ${ }^{137} \mathrm{Cs}$ with metal oxides or nutrients on particle surface coatings, concentrations of $\mathrm{Fe}, \mathrm{Mn}$ and $\mathrm{P}$ were determined on microwave digested sediment samples using ICP-OES (Foster et al., 2007) but, again, no statistically significant correlations were found between metal or nutrient content and ${ }^{137} \mathrm{Cs}$ activity. Statistically significant correlations, with $r^{2}$ values generally above $90 \%$, were produced for several mineral magnetic susceptibility and remanence properties and, more surprisingly, with loss on ignition (LOI) (Fig. 4). In order to determine whether LOI was a true reflection of organic matter concentration in the sediment, and not $\mathrm{C}$ derived from bedrock or other sources, LOI results were compared with carbon analysis undertaken using a Carlo Erba C:N analyser at Rothamsted Research, Okehampton, Devon. Correlations between $\mathrm{C}$ and LOI were almost perfect $\left(r^{2}>95 \%\right)$, clearly demonstrating that LOI was a reliable measure of down-core trends in organic matter content in this core.

The above summary raises several questions about what is controlling the relationship between ${ }^{137} \mathrm{Cs}$ activity and mineral magnetic signatures and ${ }^{137} \mathrm{Cs}$ and organic matter content. These issues are currently under further investigation. The changes in mineral magnetic signatures are indicative of a change in sediment source in these catchments (see Foster et al., 2012; Pulley et al., 2015) and also suggestive of do-

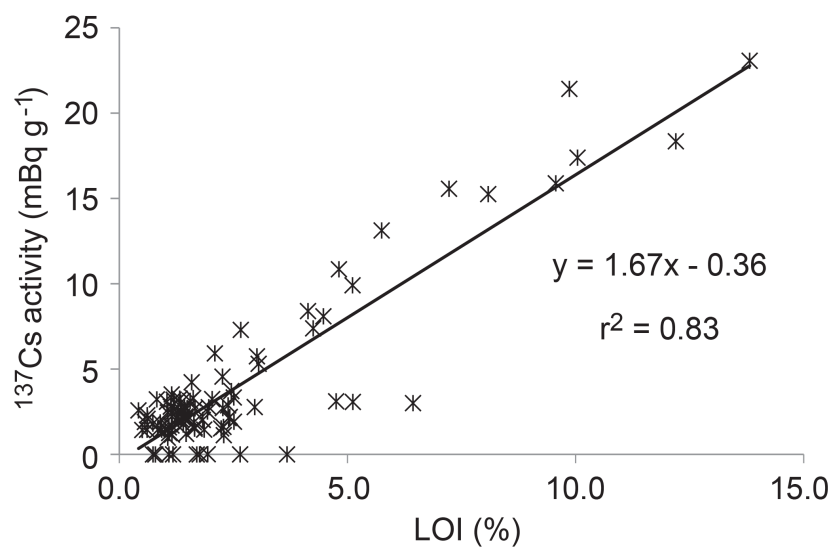

Figure 4. Relationship between LOI (\%) and ${ }^{137}$ Cs activity for the Dam 37 (Good Hope) sediment core.

lerite as being the potential source associated with the high magnetic signatures and ${ }^{137} \mathrm{Cs}$ activities. No known significant dolerite sources lie in close proximity to the Good Hope dam but further detailed reconnaissance surveys will be undertaken during future field visits in order to establish their presence. The second issue is more problematic as any of the myriad of methods that chemically remove organic matter from soil samples to establish if the ${ }^{137} \mathrm{Cs}$ is bound to it will likely attack the surface coatings of mineral grains where ${ }^{137}$ Cs may also be bound (A. Horowitz, personal communication, 2016). In order to separate organic from mineral grains we are exploring a density-based separation technique using a high density liquid (Lithium Metatungstate [LMT] SG $2.95 \mathrm{mg} \mathrm{L}^{-1}$ cut with water to a SG of $1.3 \mathrm{mg} \mathrm{L}^{-1}$ ) to physically separate the lighter organic matter from the heavier mineral soil using a non-aggressive liquid that is unlikely to chemically alter surface coatings (A. Horowitz, personal communication, 2016). The detailed protocol is currently under development, using a preliminary version developed by Rothamsted Research, but after mixing ca $2 \mathrm{~g}$ freeze-dried sediment with ca. $30 \mathrm{~mL}$ of the $1.3 \mathrm{SG}$ LMT, the suspension is centrifuged at $3000 \mathrm{rpm}$ for $1 \mathrm{~h}$ and the LMT and organic matter poured off. Analysis will be undertaken on the residual organic and inorganic fractions separated.

\section{Discussion and conclusion}

The field data presented in this paper suggest that the measurement of ${ }^{137} \mathrm{Cs}$ and other fallout radionuclides offers significant potential for dating and fingerprinting sediment sources and for providing a possible baseline date in all depositional environments that effectively provides a timesynchronous marker horizon. Sediment accumulation rates and yields could be calculated from this baseline date in order to make comparisons at the local, regional and national scale using farm dams and reservoirs ranging in size from $<1$ ha in area to large water supply reservoirs. 
Interpreting the down-core changes in ${ }^{137} \mathrm{Cs}$ activities and inventories in most cores reflects changes in sediment source, changes in particle size and/or the relative dominance of ${ }^{137} \mathrm{Cs}$ labelled topsoil sources contributing sediment to the dams. The Good Hope dam ${ }^{137} \mathrm{Cs}$ profile remains problematic and further research is being undertaken to establish whether the high activities recorded in these sediments are associated with a change in sediment source, with the way in which ${ }^{137} \mathrm{Cs}$ is chemically bound to the deposited sediment, or with the way ${ }^{137} \mathrm{Cs}$ might be preferentially moved through the catchment with very fine sediment, thereby increasing measured activities.

\section{Data availability}

The majority of the data presented here are from an ongoing and, as yet, incomplete project. We will be making all data sets available on completion of the project and will publish the results and a link to the data sets which will probably be hosted by the University of Northampton. Please contact Ian D. L. Foster for further information.

Competing interests. The authors declare that they have no conflict of interest.

Acknowledgements. Many thanks to Paul Stroud (Northampton) for re-drawing the diagrams for publication. Research reported here has been supported by the National Research Foundation (NRF) of South Africa Grant No: 85358, and Rhodes University Council Research Grant 2015-2016.

\section{References}

Boardman, J., Favis-Mortlock, D. T., and Foster, I. D. L.: A 13-year record of erosion on badland sites in the Karoo, South Africa, Earth Surf. Proc. Land., 40, 1964-1981, 2015.

Bracken, L. J., Turnbull, L., Wainwright, J., and Bogaart, P.: Sediment connectivity: a framework for understanding sediment transfer at multiple scales, Earth Surf. Proc. Land., 40, 177-188, 2015.

Clark, V. R., Barker, N. P., and Mucina, L.: The Sneeuberg: a new centre of floristic endemism on the Great Escarpment, South Africa, S. Afr. J. Bot., 75, 196-238, 2009.

Foster, I. D. L., Boardman, J., and Keay-Bright, J.: Sediment tracing and environmental history for two small catchments, Karoo uplands, South Africa, Geomorphology, 90, 126-143, 2007.

Foster, I. D. L., Collins, A. L., Naden, P. S., Sear, D. A., Jones, J. I. and Zhang, Y.: The potential for paleolimnology to determine historic sediment delivery to rivers, J. Paleolimnol., 45, 287-306, 2011.

Foster, I. D. L., Rowntree, K., Boardman, J., and Mighall, T.: Changing sediment yield and sediment dynamics in the Karoo uplands, South Africa: post - European impacts, Land Degrad. Dev., 23, 508-522, 2012.
Hoffman, M. T. and Ashwell, A.: Nature Divided: Land Degradation in South Africa, UCT Press, Cape Town, 2001.

Kulander, L. and Strömquist, L.: Exploring the use of top-soil ${ }^{137} \mathrm{Cs}$ content as an indicator of sediment transfer rates in a small Lesotho catchment, Zeit. Geomorph., 33, 455-462, 1989.

Le Roux, J. J., Newby, T. S., and Sumner, P. D.: Monitoring soil erosion in South Africa at a regional scale: review and recommendations, S. Afr. J. Sci., 103, 329-335, 2007.

Longmore, M. E., O’Leary, B. M., Rose, C. W., and Chandica, A. L.: Mapping soil erosion and accumulation with the fallout isotope caesium-137, Aust. J. Soil Res., 21, 373-385, 1983.

Loughran, R. J., Campbell, B. L., and Elliott, G. L.: The calculation of net soil loss using Caesium-137, in: Soil Erosion on Agricultural Land, edited by: Boardman, J., Foster, I. D. L., and Dearing, J. A., Chichester, Wiley, 119-126, 1990.

Owens, P. N. and Walling, D. E.: Spatial variability of Caesium-137 Inventories at Reference Sites: an Example from Two Contrasting Sites in England and Zimbabwe, Appl. Radiat. Isotopes, 47, 699-707, 1996.

Pulley, S. and Rowntree, K. M.: The use of an ordinary colour scanner to fingerprint sediment sources in the South African Karoo, J. Environ. Manage., 165, 253-262, 2016.

Pulley, S., Rowntree, K. M., and Foster, I. D. L.: Conservation of Mineral Magnetic Signatures in farm dams sediments in the South African Karoo: the potential effects of particle size and post-depositional diagenesis, J. Soil. Sediment., 15, 2387-2397, 2015.

Quine, T. A., Walling, D. E., Chakela, Q. K., Mandringana, O. T., and Zhang, X.: rates and patterns of tillage and water erosion on terraces and contour strips: evidence from caesium-137 measurements, Catena, 36, 115-142, 1999.

Rowntree, K. M.: Fluvial Geomorphology, in: Southern African Geomorphology: Recent Trends and New Directions, edited by: Holmes, P. and Meadows, M. E., Bloemfontein, Sun Press, 85140, 2012.

Rowntree, K. M. and Foster, I. D. L.: A reconstruction of historical changes in sediment sources, sediment transfer and sediment yield in a small, semi-arid Karoo catchment, South Africa. Zeit. Geomorph., 56, Suppl. 1, 87-100, 2012.

Strömquist, L. (Ed.): Monitoring soil loss at different observation levels; case studies of soil erosion in the Lesotho lowlands, Uppsala University, Department of Physical Geography UNGI Rapport Nr-74, 1991.

van der Waal, B. W.: Sediment connectivity in the upper Thina Catchment, Eastern Cape, South Africa, Unpublished PhD Thesis, Rhodes University, South Africa, 2015.

Vanmaercke, M., Poesen, J., Broeckx, J., and Nyssen, J.: Sediment yield in Africa, Earth Sci. Rev., 136, 350-368, 2014.

Walling, D. E. and Foster, I. D. L.: Using environmental radionuclides and sediment geochemistry for tracing and dating fine fluvial sediment, in: Tools in Fluvial Geomorphology 2nd edn., edited by: Kondolf, M. and Piegay, H., 183-209, Chichester, Wiley, 183-209, 2016.

Weaver, A.: Factors affecting the spatial variation in soil erosion in Ciskei: an initial assessment at the macroscale, in: Geomorphological Studies in Southern Africa, edited by: Dardis, F. G. and Moon, B. P., Rotterdam, A A Balkema, 215-228, 1988. 